\title{
Conservação pós-colheita de carambola sob refrigeração com recobrimento de biofilme de gelatina e PVC
}

\section{Postharvest conservation Star fruit refrigerated with biofilm coating gelatin and PVC}

\author{
Thiago Azevedo de Oliveira* ${ }^{1}$, Edna Maria Mendes Aroucha ${ }^{2}$, Ricardo Henrique de Lima Leite ${ }^{3}$, Rafaella Martins de Araujo
} Ferreira $^{4}$, Francisco Klebson Gomes dos Santos ${ }^{5}$

Resumo: O objetivo deste trabalho foi avaliar a Conservação pós-colheita de carambola com recobrimento de gelatina e PVC. Para isto, carambolas da cultivar 'Gigante doce' foram colhidas na maturidade fisiológica, transportadas para o Laboratório de Pós-colheita da Universidade Federal Rural do Semi-Árido sendo selecionadas quanto a maturação, sanificadas, secas e separadas em três grupos para a aplicação dos recobrimentos: os frutos foram recobertos individualmente com uma solução filmogênica de gelatina a $10 \%$ com $1 \%$ de glicerol como agente plastificante, recobertos 4 frutos com filme flexível de policloreto de vinila (PVC) de $15 \mu \mathrm{m}$ por bandeja e testemunha (sem recobrimento). Os frutos foram armazenados a $10 \pm 1{ }^{\circ} \mathrm{C} \mathrm{e}$ 85-90\% de UR, avaliados em intervalo de cinco dias durante 20 dias quanto a perda de massa, coloração da casca, firmeza de polpa, sólidos solúveis, acidez titulável, $\mathrm{pH}$ e ácido ascórbico. O delineamento experimental utilizado foi inteiramente casualizados, em esquema fatorial 3 x 5, com quatro repetições de três frutos. O recobrimento de PVC foi mais eficiente em minimizar a perda de massa dos frutos de carambola durante o armazenamento refrigerado. Enquanto, o biofilme propiciou a manutenção da coloração verde do fruto por maior período de tempo. Verificou-se aumento no teor de ácido ascórbico e decréscimo na firmeza de polpa dos frutos com o tempo de armazenamento.

Palavras-chaves: Averrhoa carambola L.; Atmosfera Modificada; Revestimento Comestível; Vida de prateleira.

Abstract: The objective of this study was to evaluate the Star fruit post-harvest preservation with coating of gelatin and PVC. For this, starfruit cultivar 'sweet Giant' were harvested at physiological maturity, transported to the Postharvest Laboratory of the Federal Rural University of the Semi-Arid being selected as maturation, sanitized, dried and separated into three groups for the implementation of coatings: the fruits were coanting individually with a film solution of gelatin to $10 \%$ with $1 \%$ glycerol as plasticizer, covered four fruits with flexible film of polyvinyl chloride (PVC) of $15 \mu \mathrm{m}$ per tray and control (without coating). The fruits were stored at $10 \pm 1{ }^{\circ} \mathrm{C}$ and $85-90 \% \mathrm{RH}$, valued at five-day intervals for 20 days as the mass loss, peel color, flesh firmness, soluble solids, titratable acidity, $\mathrm{pH}$ and ascorbic acid. The experimental design was completely randomized in a factorial $3 \times 5$, with four replications of three fruits. The PVC coating was more efficient in minimizing the mass loss of Star fruit fruit during cold storage. While the biofilm provided the maintenance of green color of the fruit for a longer period of time. An increase in the ascorbic acid content and decrease in firmness of fruit with storage time.

Key words: Averrhoa carambola L.; Modified atmosphere; Edible coating; Shelf life.

\footnotetext{
*Autor para correspondência

Recebido em 18/09/2015 e aceito em 07/11/2015

${ }^{1}$ Doutorando do Programa de Pós-Graduação em Fitotecnia, Universidade Federal Rural do Semiárido - UFERSA , Mossoró - RN, Brasil. E-mail: thiagoagrotec@hotmail.com

${ }^{2}$ Professora Adjunto do Departamento de Agrotecnologia e Ciências Sociais, Universidade Federal Rural do Semiárido - UFERSA, Mossoró - RN, Brasil. Email: aroucha@ufersa.edu.br

${ }^{3}$ Professora Adjunto do Departamento de Agrotecnologia e Ciências Sociais, Universidade Federal Rural do Semiárido - UFERSA, Mossoró - RN, Brasil. Email: ricardoleite@ufersa.edu.br

${ }^{4}$ Doutoranda do Programa de Pós-Graduação em Fitotecnia, Universidade Federal Rural do Semiárido - UFERSA , Mossoró - RN, Brasil. E-mail: rafaellamarafe@gmail.com

${ }^{5}$ Professor Adjunto do Departamento de Agrotecnologia e Ciências Sociais, Universidade Federal Rural do Semiárido - UFERSA, Mossoró - RN, Brasil. Email: klebson@ufersa.edu.br
} 


\section{INTRODUÇÃO}

A carambola (Averrhoa carambola L.) pertencente à família Oxalidaceae é originária da Ásia tropical, mais provavelmente da Índia, foi introduzida no Brasil provavelmente na região Nordeste, espalhando-se, a partir dessa região, por todo o litoral brasileiro (VENTUROSO et al., 2002).

Alguns países asiáticos, como Taiwan e Malásia, e também países sul-americanos, como o Brasil e a Colômbia, estão entre os principais exportadores para a Europa e EUA (APEXBRASIL, 2009). O volume de carambolas comercializadas no Estado de São Paulo pela CEAGESP em 2010 foi de 5.642 mil toneladas (AGRIANUAL, 2012).

O Brasil é um dos maiores produtores de carambola do mundo, sendo grande parte da produção proveniente de pequenos pomares, o que atende a um dos aspectos mais importantes da agricultura, o social, permitindo a fixação do homem no campo (NATALE et al., 2008).

Trata-se de um fruto de formato oblongo a elipsóide, com 6 a $15 \mathrm{~cm}$ de comprimento e quatro a cinco recortes longitudinais, que correspondem aos carpelos, a casca é translúcida, lisa e brilhante, e a cor varia do esbranquiçado ao amarelo-ouro intenso (WILSON, 1990).

A qualidade das frutas está em função da cultivar especifica e os fatores climáticos e culturais de manejo da planta. As características físico-químicas de carambolas detectados na região semiárida do nordeste por Torres et al. (2003) variaram conforme o estádio de maturação (verde, semi-madura e madura, respectivamente), para o teor de sólidos solúveis $(5,5 ; 7,0$ e $8,0 \%), \mathrm{pH}(3,52 ; 3,61$ e 3,69$)$ e acidez titulável $(0,41 ; 0,38$ e $0,37 \mathrm{mg}$ de ácido cítrico por $100 \mathrm{~g}$ de polpa).

O'Hare (1993) relatou que existem conflitos na literatura sobre o padrão respiratório da carambola. Para Vines; Grierson (1966) e Shiesh,; Lien e Tsai. (1987) a carambola é climatérica, enquanto que outros pesquisadores (OSLUND; DAVENPORT, 1983; LAM; WAN, 1987 e MITCHAN; McDONALD, 1991) não encontraram o pico climatérico. Estes autores não observaram elevações apreciáveis na respiração e quando ocorreu, foi associada a doenças.

A atmosfera modificada é aplicada para uma grande quantidade de frutos, normalmente obtida através do uso de filmes plásticos flexíveis (PVC, polietileno de baixa densidade, e polipropilento) que visa reduzir a respiração e produção de etileno dos frutos através da alteração da concentração inicial dos gases dentro da embalagem (OLIVEIRA-JR et al., 2005) o seu uso associado com a refrigeração na temperatura adequada constitui-se a tecnologia mais eficiente para armazenamento dos produtos vegetais, a faixa de temperatura de armazenamento de carambola é de 5 a $10^{\circ} \mathrm{C}$ (LOWNDS et al., 1994).

Essas técnicas mantém a qualidade de frutas e hortaliças por maior período de tempo, por reduzir a atividade metabólica e perda de água (VILA, 2007). Já que modifica a atmosfera interior da embalagem, propiciando níveis baixos de $\mathrm{O}_{2}$ e elevados de $\mathrm{CO}_{2}$ (FAKHOURI, at al., 2007).

$\mathrm{O}$ uso de filmes plásticos, associado à baixa temperatura, é prática bastante utilizada pelas empresas agrícolas na exportação de alguns frutos. O uso de PVC (policloreto de vinila) é bastante comum em revestimento de frutas mais sensíveis como caju (MORAIS et al., 2002). Por outro lado, o uso de filmes e coberturas comestíveis e/ou biodegradáveis vem sendo uma alternativa tecnológica atraente para a conservação de frutas, por não poluir o ambiente e, ainda possibilitar incremento na qualidade dos alimentos (FAKHOURI et al., 2007; AMARIZ et al., 2010; CASTRICINI et al., 2012; PARK, 1999).

Nesse sentido, filmes e/ou coberturas comestíveis preparados a partir de polímeros naturais, como, polissacarídeos (amido, carragenina, alginatos, etc) e proteínas (gelatina, caseína, glúten de trigo, etc) com a adição de plastificantes (glicerol, sobitol, sacarose, etc) para redução a característica quebradiça do polímeros (FAKHOURI et al., 2012; FAKHOURI et al., 2009; DAVANÇO et al, 2007), têm sido testados com relação a sua viabilidade no prolongamento da vida útil pós-colheita de frutas. Dessa forma, o presente trabalho teve por objetivo avaliar a conservação pós-colheita de carambola sob refrigeração com recobrimento de biofilme de gelatina e PVC.

\section{MATERIAL E MÉTODOS}

Carambolas da cultivar 'Gigante doce' foram colhidas na maturidade fisiológica (coloração verde clara), na Empresa Agrícola JS Tropical Comércio de Frutas Ltda, localizada no município de Limoeiro-CE. Em seguida foram transportados para o Laboratório de Pós-Colheita da Universidade Federal Rural do Semiárido (UFERSA), onde foram submetidos a uma lavagem com hipoclorito de sódio a $100 \mathrm{ppm}$ por 15 minutos e secos em temperatura ambiente. Após foram selecionados com peso médio de $88,25 \pm 5,88$ g, quanto à uniformidade de maturação e ausência de defeitos, ferimentos e ataque de microrganismos.

Assim os frutos foram subdivididos em três grupos para a aplicação dos tratamentos: revestimento comestível a base de gelatina a $10 \%$ com $1 \%$ de plastificante glicerol, filme plástico (atmosfera modificada) de PVC $(15 \mu \mathrm{m})$ e testemunha (sem recobrimento),

O revestimento comestível foi obtido após hidratação de $100 \mathrm{~g}$ de gelatina (tipo A, bloom $=244$, marca Ômega) e $10 \mathrm{~g}$ de glicerol em 1 litro de água destilada, durante 1 hora em temperatura ambiente para intumescer. Após, a solução foi agitada e aquecida a uma temperatura de $60{ }^{\circ} \mathrm{C}$, durante 10 minutos, com o auxílio de um aquecedor-agitador. Os frutos foram imersos na solução com temperatura de $25^{\circ} \mathrm{C}$, e secos em temperatura ambiente.

Após a pesagem das bandejas contendo 4 frutas cada, as mesmas foram submetidas à refrigeração $\left(10 \pm 1^{\circ} \mathrm{C}\right.$ e $85 \pm 2 \%$ de U.R.), por 20 dias, em câmaras que eram diariamente monitoradas através de um termohigrômetro. No tempo 0 (colheita) e a cada intervalo de cinco dias, quatro bandejas com três frutos cada foram retirados, pesadas e avaliados quanto a perda de massa - em balança semi-analítica; firmeza da polpa - com penetrômetro manual FT011, realizada em quatro pontos da região longitudinal dos frutos; coloração da casca - escala de notas de $1-5(5=100 \%$ cor verde clara, $4=$ $25 \%$ de cor amarela, $3=50 \%$ de cor amarela, $2=75 \%$ de cor amarela, $1=100 \%$ de cor amarela) sendo realizada por 5 avaliadores; sólidos solúveis (SS) utilizando refratômetro digital e os resultados expressos ${ }^{\circ}$ Brix; $\mathrm{pH}$ - conforme metodologia do Instituto Adolfo Lutz (1985); acidez titulável - utilizou-se a metodologia recomendada pela AOAC (1992), ácido ascórbico - determinado por titulometria e os resultados 
expressos em mg de ácido ascórbico por $100 \mathrm{~g}$ de polpa, conforme o método 43.064 descrito pela AOAC (1992).

$\mathrm{O}$ experimento foi conduzido em delineamento inteiramente casualizado (DIC), em esquema fatorial $3 \times 5$ (revestimento $\mathrm{x}$ tempo de armazenamento), com quatro repetições (bandejas) de três frutos cada. A partir dos resultados preliminares da análise de variância, verificando-se interação significativa entre os fatores, o tempo foi desdobrado dentro de cada tratamento e os resultados submetidos à regressão polinomial, considerando-se equações de até $2^{\circ}$ grau. As médias de aplicação do revestimento comestível a base de gelatina, quando significativas, foram comparadas pelo teste de tukey a $5 \%$ de probabilidade. As análises de regressão foram efetuadas usando-se programa de análise estatística Sisvar (FERREIRA, 2000).

\section{RESULTADOS E DISCUSSÃO}

Houve interação significativa entre os fatores recobrimento e tempo de armazenamento somente quanto à perda de massa e coloração dos frutos, indicando comportamento diferenciado dos dois níveis do fator recobrimento nos diferentes tempos de armazenamento (Tabela 1). Observou-se efeito isolado do revestimento e tempo apenas para o ácido ascórbico. Verificou-se efeito de tempo de armazenamento para quase todas as características estudadas, a única exceção foi sólidos solúveis.

A presença da interação evidencia a dependência entre os dois fatores e exige um estudo mais aprofundado pelo desdobramento dos níveis de um fator em função dos níveis de um segundo fator. Por outro lado, a ausência da interação permite que os dois fatores sejam estudados independentemente.

Tabela 1 - Valores de "F" para Perda de massa (PM) Cor (CO), pH, acidez titulável (AT), sólidos solúveis (SS), firmeza de polpa (FP), e Ácido ascórbico (AA) de carambolas da cultivar Gigante Doce' recobertos com biofilme de gelatina e PVC, durante o armazenamento a $10^{\circ} \mathrm{C}$.

\begin{tabular}{lccccccc}
\hline Fonte de Variação & PM & $\mathrm{CO}$ & $\mathrm{pH}$ & $\mathrm{AT}$ & $\mathrm{SS}$ & $\mathrm{FP}$ & AA \\
\hline Recobrimento (R) & $89,19^{* *}$ & $1,55^{\mathrm{ns}}$ & $1,25^{\mathrm{ns}}$ & $0,12^{\mathrm{ns}}$ & $2,33^{\mathrm{ns}}$ & $1,16^{\mathrm{ns}}$ & $11,42^{* *}$ \\
Tempo (T) & $59,47^{* *}$ & $76,27^{* *}$ & $4,97^{*}$ & $13,41^{* *}$ & $2,34^{\mathrm{ns}}$ & $17,97^{* *}$ & $78,98^{* *}$ \\
R X T & $11,16^{* *}$ & $4,78^{* *}$ & $1,32^{\mathrm{ns}}$ & $1,52^{\mathrm{ns}}$ & $1,33^{\mathrm{ns}}$ & $0,34^{\mathrm{ns}}$ & $2,66^{\mathrm{ns}}$ \\
\hline C.V. $(\%)$ & 34,24 & 15,90 & 8,43 & 7,85 & 6,23 & 15,22 & 9,71 \\
\hline
\end{tabular}

* Significativo ao nível de $5 \%$ de probabilidade. ${ }^{* *}$ Significativo ao nível de $1 \%$ de probabilidade. ${ }^{\text {ns }}$ não significativo.

Observou-se acréscimo na perda de massa ao longo do tempo de armazenamento nos frutos com e sem recobrimento (Figura 1). Verificou-se nos frutos testemunha (sem recobrimento) e recobertos com biofilme maior perda de massa por unidade de tempo quando comparado aos frutos revestidos com PVC. Esse fato resultou em melhor aparência ao final do tempo de armazenamento para os frutos acondicionados em PVC. A perda de massa dos frutos testemunha foi $6,27 \%$, enquanto nos frutos revestidos com biofilme foi $5,92 \%$, sendo superiores a perda de massa verificada nos frutos com PVC $(0,87 \%)$ no final do período de armazenamento. A ótima barreira à passagem de vapor de água do fruto para a atmosfera representada pelo uso do filme policloreto de vinila está relacionado com as moléculas hidrofóbicas em sua constituição, evitando a perda de massa dos frutos durante transporte pós-colheita (KADER, 2002).

A perda de massa que se relaciona à perda de água é causa principal da deterioração e perdas quantitativas e qualitativas dos frutos, pois altera negativamente a aparência e qualidades texturais (amaciamento, perda de frescor e suculência), tornando-os pouco atrativos para a comercialização e consumo (KADER, 2002). .

Figura 1. Perda de massa de frutos de caramba recobertos com biofilme de gelatina e filme plástico PVC $15 \mu \mathrm{m}$, durante o armazenamento a $10^{\circ} \mathrm{C}$.

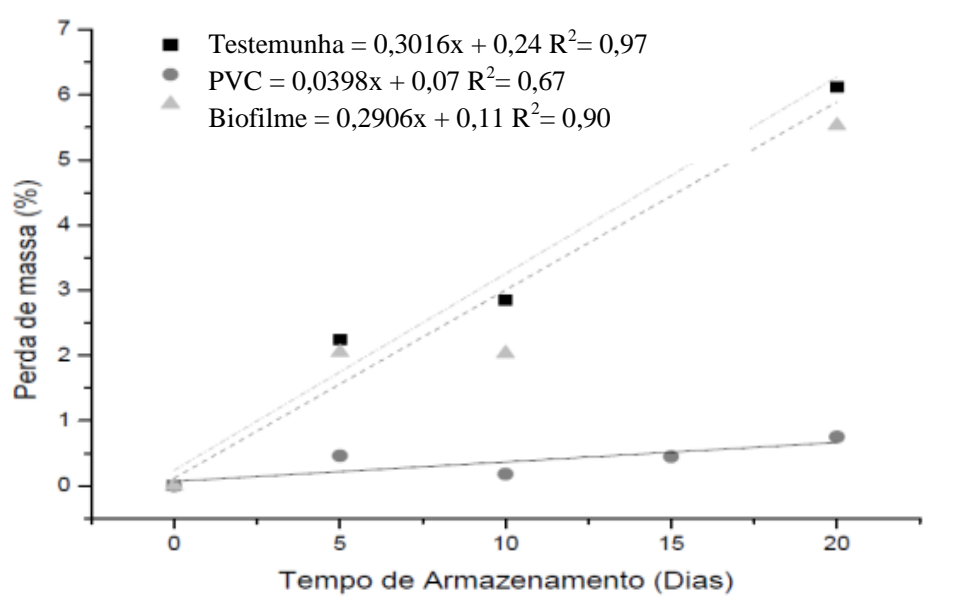


A tecnologia de uso do biofilme não foi eficiente como barreira à passagem de água, sendo detectada melhor barreira o filme de PVC (perda de massa inferior a 1\%). Resultados semelhante foram encontrados com o uso de PVC no recobrimento de caju (MORAIS et al., 2002) e mangas Tommy Atkins e Espada vermelha (SOUSA et al., 2002; PFAFFENBACH et al., 2003). Oliveira et al. (2011) verificaram com o uso de biofilme de gelatina a $10 \%$ no revestimento de tomate, mantidos em temperatura ambiente, aumento na perda de água dos frutos comparado com a testemunha. Isso está associado possivelmente ao seu caráter higroscópico (FAKHOURI et al., 2007) que permite livre permeação do vapor d'água proveniente do fruto para a atmosfera. A transpiração natural do fruto, associado à perda de carbono pela respiração dos frutos (KADER, 2002) pode explicar a perda de massa durante o tempo de armazenamento.

Kader (1999) relatou que perdas de massa de até 5\% para carambolas não afetam a aparência e a comercialização. Oliveira-Júnior et al. (2006) argumentam que a espessura do polímero de PVC acarreta aumento da umidade relativa no interior das embalagens, levando à diminuição do déficit de pressão de vapor d'água o que reduz a transpiração dos frutos.

Desdobrando os períodos de armazenamento dentro de cada tratamento, verifica-se que houve redução na cor dos frutos de carambola em todos os tratamentos (Figura 2), respectivamente.

Figura 2. Estimativa da perda de coloração frutos de carambolas cobertos com biofilme de gelatina e PVC durante o armazenamento refrigerado.

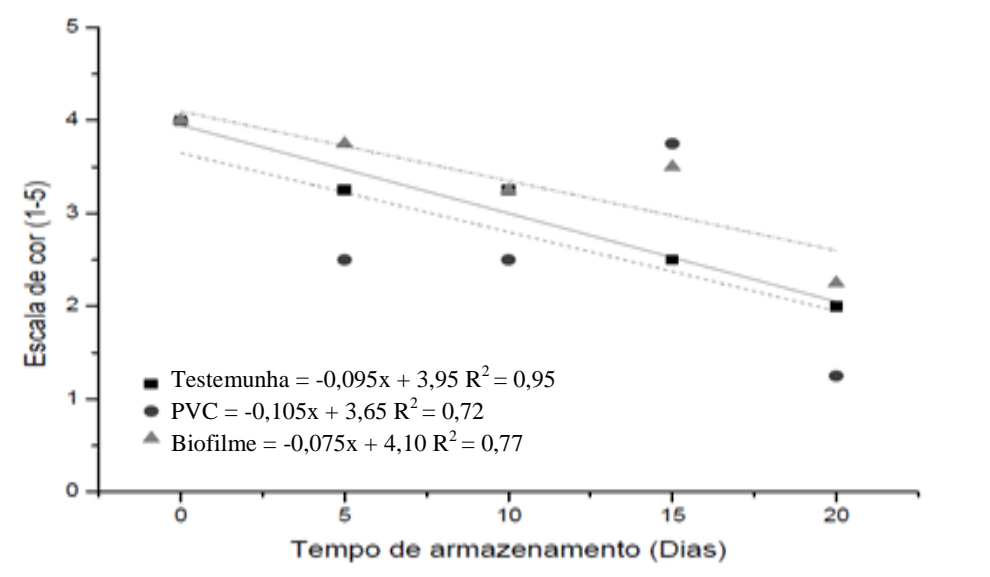

Concernente à coloração dos frutos, observou-se declínio linear ao longo do período de armazenamento (Figura 2). Ao contrário do que foi observado para a perda de massa, os comportamentos da coloração ao longo do tempo de armazenamento em frutos sem revestimento (testemunha) e revestidas com PVC apresentaram notas inferiores $(2,05 \mathrm{e}$ $1,55)$ daquelas armazenadas com revestimento de biofilme $(2,60)$ no final do período de armazenamento. Tal comportamento pode ser explicado (SOUZA et al., 2002; NEVES et al., 2002; YAMASHITA et al., 2002), pelo fato da embalagem, quando corretamente projetada, diminuir a taxa de degradação dos pigmentos dos frutos proporcionando a manutenção da maturação.

Os frutos sem revestimento e recobertos apresentam redução na coloração dos frutos. Entretanto, o biofilme de gelatina se sobressaiu em todos os períodos de armazenamento, por evitar a perda de coloração (Figura 2). Isto evidencia que a constituição da molécula protéica de gelatina propiciou maior barreira à passagem de gases $\left(\mathrm{O}_{2} \mathrm{e}\right.$ $\mathrm{CO}_{2}$ ), o que reduz o metabolismo do fruto. De acordo com Davanço et al. (2007) biofilmes elaborados a partir de proteínas são boas barreiras ao $\mathrm{O}_{2}$ e $\mathrm{CO}_{2}$ em ambientes com baixa umidade relativa.

Verificaram-se nos frutos revestidos com PVC e biofilme teores de ácido ascórbico inferiores $(8,58 \%)$ quando comparados aos frutos sem recobrimento (Tabela 2). A mudança na atmosfera normal do fruto, provocada pelo uso do biofilme e PVC, alterou os teores de ácido ascórbico durante o período de armazenamento. Sancho (2006) argumenta que a síntese do ácido ascórbico pode ocorrer tanto em condições aeróbica quanto anaeróbica; porém em menor quantidade de oxigênio no meio haverá uma síntese reduzida dessa vitamina.

Tabela 2. Valores médios do ácido ascórbico de frutos de arambola, durante o armazenamento refrigerado. UFERSA, Mossoró/RN, 2010

\begin{tabular}{lc}
\hline Amostra & Ácido Ascórbico \\
\hline Testemunha & $25,75 \mathrm{a}$ \\
PVC & $22,53 \mathrm{~b}$ \\
Biofilme & $23,54 \mathrm{~b}$ \\
\hline
\end{tabular}

DMS = 1,90; MG = 23,94; $\mathrm{CV}(\%)=6,88$ obs: MG Média geral; $\mathrm{CV}$ Coeficiente de variação e DMS Desvio mínimo significativo. Obs.: médias seguidas pelas mesmas letras não diferem estatisticamente pelo teste de Tukey a nível de $5 \%$ de probabilidade.

Por outro lado, verifica-se acréscimo linear do ácido ascórbico em função do tempo de armazenamento dos frutos independente do revestimento (Figura 3). Segundo Chitarra \& Chitarra (2005) alguns frutos aumentam o teor de ácido ascórbico durante o amadurecimento (caju), enquanto outros diminuem (acerola). Pose-se notar que houve um incremento de $80 \%$ no teor de ácido ascórbico durante o armazenamento. Comportamentos semelhantes foram verificados durante o amadurecimento de carambola por Araújo (2009). Ao contrário, Teixeira et al. (2007) verificaram redução nos teores de ácido ascórbico após 15 dias de armazenamento, de 16,34 para $12,65 \mathrm{mg} .100 \mathrm{~g}-1$ de polpa. 
Figura 3. Estimativa de Ácido ascórbico de frutos de carambola, durante o armazenamento refrigerado.

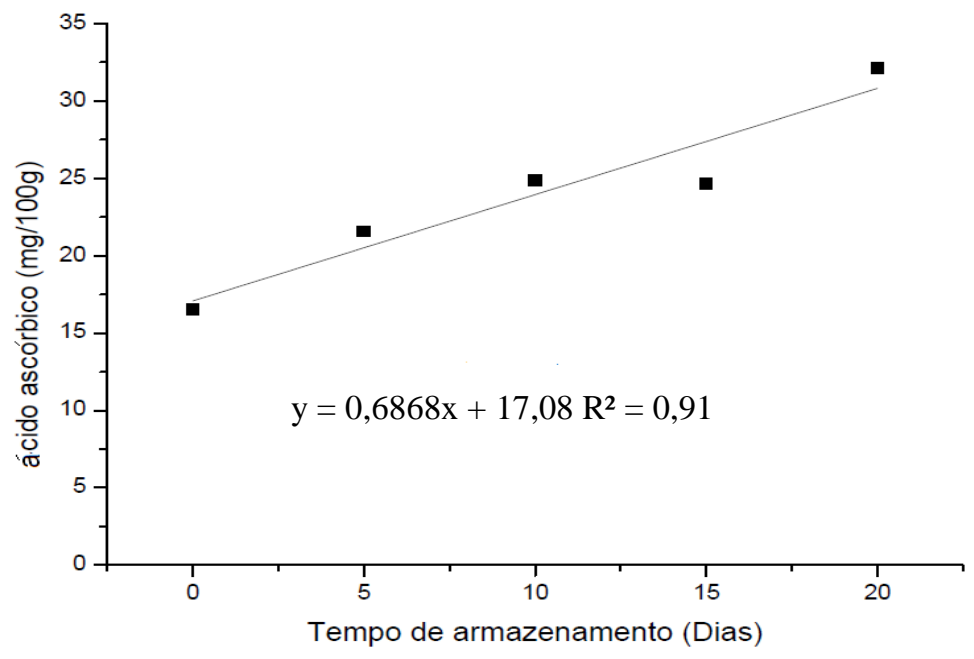

Verificou-se aumento de $11 \%$ para acidez titulável até os 15 dias de armazenamento e redução após esse período. De mesma maneira, Ogassavara et al. (2009) verificaram na cultivar de carambola 'Nota 10', um incremento na acidez titulável durante o armazenamento. Enquanto, Oliveira et al. (2010) detectaram diminuição na acidez das carambolas, durante o armazenamento, o que associaram ao processo normal de evolução da maturação, na qual os ácidos orgânicos são metabolizados pela via respiratória e convertidos em moléculas não ácidas. Tal resultado (Figura 4) foi evidenciado, neste trabalho, aos 20 dias de armazenamento.

Esse decréscimo era esperado uma vez que após a colheita, a concentração de ácidos orgânicos tende a declinar na maioria dos frutos, devido à larga utilização desses compostos como substrato respiratório e como esqueleto de carbono para a síntese de novos compostos, enfatizam Kays (1991). Entretanto, quando armazenados sob condições atmosféricas limitantes de $\mathrm{O} 2$, havendo processo fermentativo pode ocasionar um aumento no teor de ácidos (CHITARRA; CHITARRA, 2005). Na maioria dos frutos a acidez titulável representa um dos principais componentes do flavor, pois sua aceitação depende do balanço entre ácidos e açúcares (CHITARRA; CHITARRA, 2005). A acidez titulável encontrada em carambola, na literatura, é de 0,16 a $0,53 \%$ ácido cítrico (OLIVEIRA et al., 2010; OGASSAVARA et al., 2009; TEIXEIRA et al,. 2007; TORRES, et al,. 2003; TEIXEIRA et al,. 2001).

Figura 4. Estimativa de acidez titulável de frutos de carambolas, durante o armazenamento refrigerado.

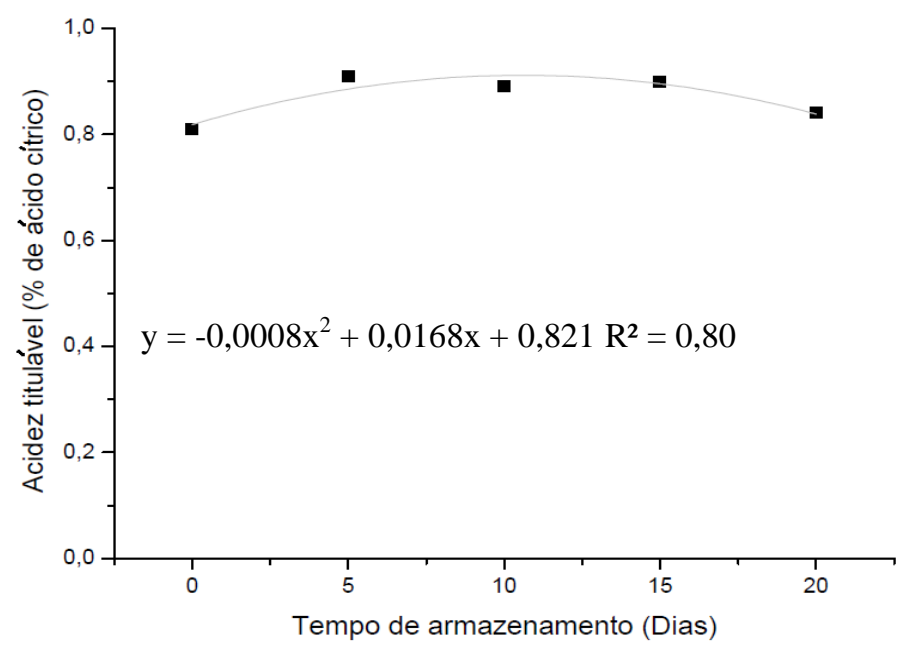

$\mathrm{O} \mathrm{pH}$ dos frutos variou em função do tempo de armazenamento, independentemente do recobrimento (Figura 5). Observa-se decréscimo de $\mathrm{pH}$ até 10 dias, seguido por um leve incremento após esse período. O que pode ser explicado uma vez que a acidez dos frutos diminuiu, no final do armazenamento. Ao contrário dos resultados detectados no presente trabalho, Teixeira et al. (2007) não detectaram diferenças entre o $\mathrm{pH}$ de carambolas durante o armazenamento, ao qual variou de 3,91 a 4,08.

Os frutos apresentaram $\mathrm{pH}$ médio de 1,63, com variação de $12 \%$ no $\mathrm{pH}$ ao longo do armazenamento (Tabela 1). $\mathrm{O} \mathrm{pH}$ da carambola varia, normalmente, enfatiza Kader (1999), com o grupo a que pertence, as cultivares do grupo doce apresentam $\mathrm{pH}$ de 3,8 a 4,1, enquanto as do grupo ácida possuem $\mathrm{pH}$ de 2,2 a 2,6 . 
Figura 5. Estimativa do $\mathrm{pH}$ de frutos de carambola, durante o armazenamento refrigerado.

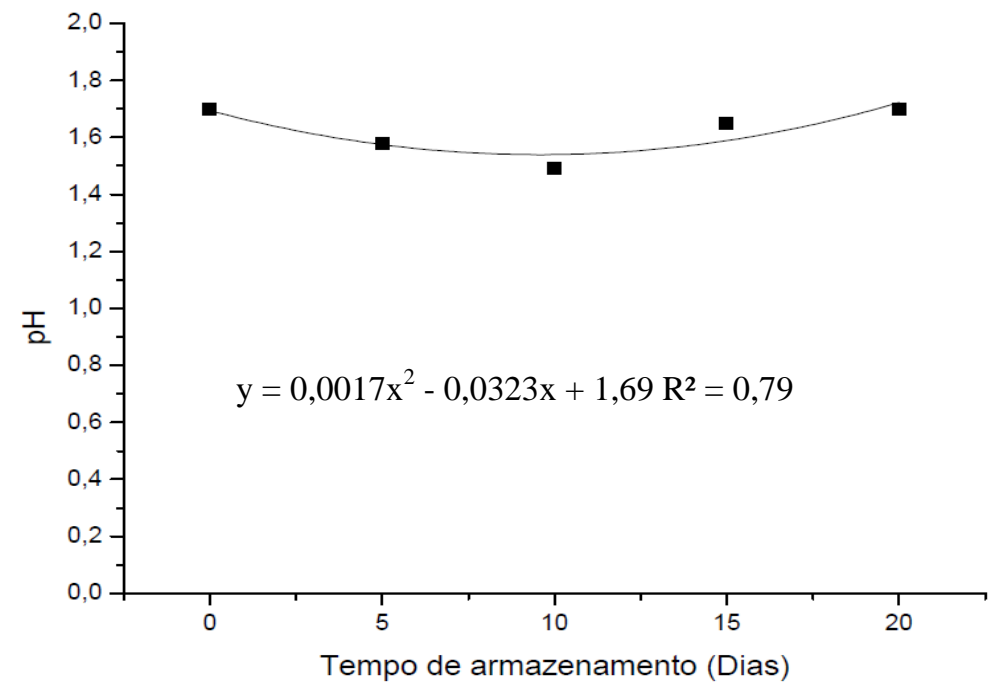

A firmeza da polpa diminuiu com o tempo de armazenamento independentemente do recobrimento dos frutos (Figura 6), sendo que a redução mais acentuada ocorreu a partir do décimo dia de armazenamento, reduzindo de 18,78 para 12,05 $\mathrm{N}$ aos 20 dias. Dentre as causas principais da redução na firmeza de polpa de carambola, está a degradação da lamela média, da parede primária, com conseqüente aumento da pectina solúvel e perda de açúcares neutros nãocelulósicos (JACOMINO et al., 2002) evidentes nos estádios mais avançados do amadurecimento.

Em carambolas, a perda de firmeza durante o amadurecimento está relacionada com o aumento na atividade de várias enzimas que degradam a parede celular, particularmente a pectinametilesterase e $\beta$-galactosidase. Poligalacturonase e $\beta$-glucanase, entretanto, aumentaram a atividade numa segunda fase de maturação, sugerindo que elas podem ter um importante papel em estádios mais adiantados do amadurecimento (CHIN et al.,1999). O'hare (1993) observou uma relação inversa entre firmeza dos frutos de carambola e atividade da enzima poligalacturonase, além de verificar que a atividade enzimática foi maior nos frutos totalmente maduros.

Figura 6. Estimativa de firmeza de polpa de frutos de carambolas, durante o armazenamento refrigerado.

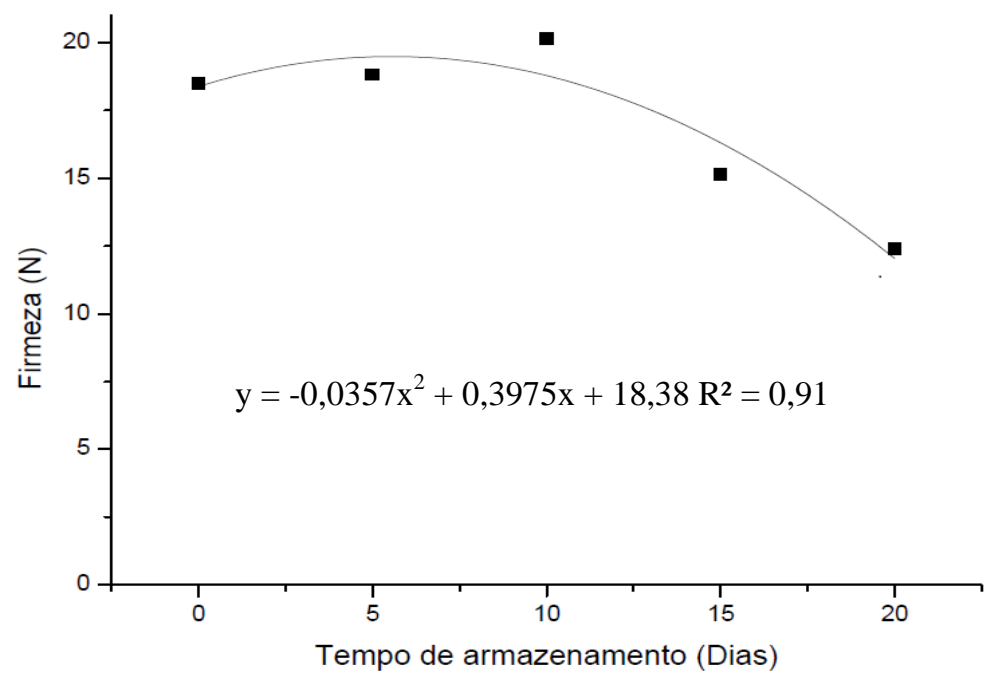

Não se observou efeito de embalagem e nem tempo de armazenamento sobre o teor de sólidos solúveis (Tabela 1) os valores médios encontrados para os revestimentos e períodos

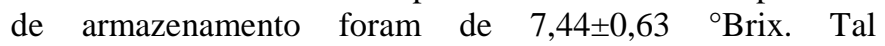
comportamento foi relatado, também, em carambola 'Fwang Tung' por Teixeira et al. (2007), quando os frutos foram revestidos com diferentes embalagens e por Neves et al. (2004) durante o armazenamento de carambola azeda 'Golden Star'em atmosfera passiva.

\section{CONCLUSÕES}

A utilização de PVC foi mais eficiente em minimizar a perda de massa dos frutos de carambola durante o armazenamento refrigerado. Enquanto, o biofilme propiciou a manutenção da coloração verde do fruto por maior período de tempo. Verificou-se aumento no teor de ácido ascórbico e 
decréscimo na firmeza de polpa dos frutos com o tempo de armazenamento.

\section{REFERÊNCIAS BIBLIOGRÁFICAS}

AGRIANUAL 2012: Anuário da agricultura brasileira. São Paulo: Instituto FNP, 2011. 512p.

AMARIZ, A.; LIMA, M. A. C.; TRINDADE D. C. G.; SANTOS, A. C. N.; RIBEIRO, T. P. Recobrimentos à base de carboximetilcelulose e dextrina em mangas 'Tommy Atkins' armazenada sob refrigeração. Ciência Rural, v. 40, p.2199-2205, 2010.

AOAC - Official methods of analysis of the Association of Official Analytical Chemistry. 11 ed. Washington: AOAC, 1992.1115p.

APEXBRASIL. Diversidade brasileira na Fruit Logística 2009. <http://www.apexbrasil.com.br/portal/publicacao/en gine.wsp?tmp.area $=416 \&$ tmp.texto $=889 \&$ tmp.area_anteri or=416\&tmp.argumento_pesquisa=Diversidade $\% 20$ brasil eira\%20na\%20Fruit\%20Log\%EDstica\%202009\&tmp.url passada=416_Diversidade\%20brasileira\%20na\%20Fruit $\%$ 20Log\%EDstica\%202009>.15 dez. 2011.

ARAÚJO E. R; FARIAS G. A; SAPUCAY M. J. L. C; SILVA P. K; COLARES P. N. Q; MEDEIROS M. S; PEDROZA C. M; RÊGO E. R; RÊGO, M. M. Mudanças em características físicas e químicas de carambola durante a maturação. Horticultura Brasileira. v.27 p.S1156-S1160. 2009.

CAMPBELL, C. A.; KOCH, K. E. Sugar/acid composition and develompment of sweet and tart carambola fruit. Journal of American Society for Horticultural Science, Alexandria, v.114, p.455-7, 1989.

CASTRICINI, A.; CONEGLIAN, R. C. C.; DELIZA, R. Starch edible coating of papaya: effect on sensory characteristics. Ciência e Tecnologia de Alimentos. v.xxx, p.0-0, 2012.

CHIN, L. H.; ALI, Z. M.; LAZAN, H. Cell wall modifications, degrading enzymes an softening of carambola fruit during ripening. Journal of Experimental Botany, v. 50. p.767-775. 1999.

CHITARRA, M. I. F.; CHITARRA, A. B. Pós colheita de frutas e hortaliças: fisiologia e manuseio. 2 ed. Lavras: UFLA, 2005. 785p.

DAVANÇO, T.; TANADA-PALMU, P.; GROSSO, C. Filmes compostos de gelatina, triacetina, ácido esteárico ou capróico: efeito do $\mathrm{pH}$ e da adição de surfactantes sobre a funcionalidade dos filmes. Campinas, Ciência Tecnologia Alimentos, v.27. p.408-416, 2007.

DONADIO, L. C.; SILVA, J. A A.; ARAÚJO, P. S.; PRADO, R. M. Caramboleira (Averrhoa carambola L.). Jaboticabal: Sociedade Brasileira de Fruticultura, 2001. 81 p. Série frutas potenciais.
FAKHOURI F. M.; FONTES, L. C. B.; GONÇALVES, P. V. M.; MILANEZ, C. R.; COLLARES-QUEIROZ, F. P. Filmes e coberturas comestíveis compostas à base de amidos nativos e gelatina na conservação e aceitação sensorial de uvas Crimson. Ciência e Tecnologia de Alimentos, v.27, p.369-375, 2007.

FAKHOURI F. M.; FONTES, L. C. B.; MEI, L. H. I.; QUEIROZ, F. P. C. Effect of Fatty Acid Addition on the Properties of Biopolymer Films Based on Lipophilic Maize Starch and Gelatin. Starch. v.6,1p.528-536, 2009.

FAKHOURY, F. M.; MARTELLI, S. M.; BERTAN, L. C.; YAMASHITA, F.; MEI, L. H. I.; QUEIROZ, F. P. C. Edible films made from blends of manioc starch and gelatin - influence of different types of plasticizer and different levels of macromolecules on their properties. LWT - Food Science and Technology. v.4, p.0-0. 2012.

FERREIRA, D. F. Manual do sistema Sisvar para análises estatísticas. Lavras, Universidade Federal de Lavras, 2000. 66p.

INSTITUTO ADOLFO LUTZ. Normas analíticas, métodos químicos e físicos para análise de alimentos. 3. ed. São Paulo: Instituto Adolfo Lutz, v.1, 1985. 533 p.

JACOMINO, A. P.; KLUGE, R. A.; BRACKMANN, A.; CASTRO, P. R. C. Amadurecimento e senescência de mamão com 1- metilciclopropeno. Scientia Agrícola, v.59, p.303-308, 2002.

KADER, A. A. Carambola (Star fruit). produce facts. Davis: Perishables Handling Quarterly UC. Davis, no.93, Davis CA, 1999. p.19-20.

KADER A. A (3Ed.). Postharvest Technology of Horticultural Crops (3rd Edition), 2002.

KAYS, J. S. Postharvest physiology of perishables plant products. New York: AVI, 1991. 543p.

LAM, P. F.; WAN, C. K. Climacteric nature of the carambola (Averrhoa carambola L.) fruit. Pertanika, Selangor, v. 6, n. 3, p. 44-47, 1983.

LOWNDS N. K.; BANARAS M.; BOSLAND P. W. Postharvest water loss and storage quality of nine pepper (Capsicu) Cultivar). HortScience, v. 29, p. 191-193. 1994.

MITCHAM, E. J.; McDONALD, R. E. Characterization of the ripening of carambola (Averrhoa carambola L.) fruit. Proceedings of Florida State Horticultural Science, Winter Haven, v. 104, p. 104-108, 1991.

MORAIS, A. S.; MAIA, G. A.; FIGUEIREDO, R. W.; ALVES, R. E.; FILGUEIRAS, H. A. C.; MOURA, C. F. H. Armazenamento refrigerado sob atmosfera modificada de pedúnculos de cajueiro-anão-precoce dos clones ccp76, end-157, end-183 e end-189. Revista Brasileira de Fruticultura, v.24, p. 647-650, 2002. 
NATALE, W.; PRADO, R. M.; ROZANE, D. E.; ROMUALDO, L. M.; SOUZA, H. A. DE; HERNANDES, A. Resposta da caramboleira à calagem. Revista Brasileira de Fruticultura, v.30, p.1136-1145, 2008.

NEVES, L. C.; BENDER, R. J.; ROMBALDI, C. V.; VIETES, R. L. Armazenagem em atmosfera modificada passiva de carambola azeda (Averrhoa carambola L.) cv. 'golden star'. Revista Brasileira de Fruticultura, v.26, p.13-16, 2004.

NEVES, L. C.; RODRIGUES, A. C.; VIEITES, R. L. Polietileno de baixa densidade (PEBD) na conservação pós-colheita de figos cv. "Roxo de Valinhos". Revista Brasileira de Fruticultura, v.24, p.57-62, 2002.

O'HARE, T. J. Postharvest physiology and storage of carmbola (starfruit): a review. Postharvest Biology and Technology, v.2, p.257-267, 1993.

OGASSAVARA, F. O.; DURIGAN, J. F.; TEIXEIRA, G. H. A.; CUNHA-JÚNIOR, L. C. Comparação entre cultivares de carambola para produção de produtos minimamente processados. Revista Brasileira de Fruticultura, v.31, p.544-551, 2009.

OLIVEIRA JÚNIOR, L. F. G.; COELHO, E. M.; COELHO, F. C. Caracterização pós-colheita de mamão armazenado em atmosfera modificada. Revista Brasileira de Engenharia Agrícola e Ambiental, v.10, p.660-664, 2006.

OLIVEIRA, L. F. G.; SANTOS, P. N.; CANA, E.; LOURENÇO-JR, J.; RODRIGUES, S. Utilização da atmosfera modificada na conservação pós-colheita de carambola. Global Science and Technology, v.03, p.4959,2010

OLIVEIRA, T. A.; LEITE, R. H. L.; AROUCHA, E. M. M.; FERREIRA, R. M. A. Efeito do revestimento de tomate com biofilme na aparência e perda de massa durante o armazenamento. Revista Verde v.6, p.230-234, 2011.

OSLUND, C. R.; DAVENPORT, T. L. No climacteric in the star fruit (Averrhoa carambola). Horticultural Science, Alexandria, v. 16, n. 3, p. 424, 1981.

PARK, H.J. Development of advanced edible coatings for fruits. Trends in Food Science and Technology, v.10, p.254-260, 1999.

PFAFFENBACH, L. B.; CASTRO, J. V. DE; CARVALHO, C. R. L.; ROSSETTO, C. J. Efeito da atmosfera modificada e da refrigeração na conservação pós-colheita de manga espada vermelha. Revista Brasileira de Fruticultura. v.25 p.410-413, 2003.

SANCHO, S. O. Efeito do processamento sobre características de qualidade do suco de caju (Anacardium occidentale L.). Fortaleza: Universidade Federal do Ceará. 2006. 138p. Dissertação Mestrado.
SHIESH, C.C.; LIN, T .S.; TSAI, P. L. Respiration and ethylene production of harvested carambola fruits (Averrhoa carambola L.). J. Chinese Soc. Hort. Sci. 33:139-150, 1987.

SOUSA, J. P.; PRAÇA, E. F.; ALVES, R. E.; NETO, F. B. DANTAS. F. F. Influência do armazenamento refrigerado em associação com atmosfera modificada por filmes plásticos na qualidade de mangas 'Tommy Atkins. Revista Brasileira de Fruticultura, v.24, p.665-668, 2002.

TEIXEIRA, G. H. A.; DURIGAN, J. F.; ALVES, T. E. Qualidade de Frutos de Carambola após Tratamento Térmico. Brazilian Journal Food Technology. v.10, p. 4350, 2007.

TEIXEIRA, G. H. A.; DURIGAN, J. F.; DONADIO, L. C.; SILVA, J. A. A. Caracterização pós-colheita de seis cultivares de carambola (Averrhoa Carambola L.). Revista Brasileira de Fruticultura. v.23, p. 546-550, 2001.

TORRES, L. B. V.; FIGUEIRÊDO, R. M. F.; QUEIROZ, A. J. M. Caracterização química de carambolas produzidas em região semi-árida do nordeste brasileiro. Revista Brasileira de Produtos Agroindustriais, v.Especial, p.4354, 2003.

VENTUROSO, J. R. A.; RUEDA, W. C.; SAMPAIO, R. M.; MARCOS, S. K. Estudo da secagem de carambola (Averrhoa carambola L.). In: Congresso Brasileiro de Ciência e Tecnologia de Alimentos, 2002, Porto Alegre, Anais. Porto Alegre: SBCTA, 2002. CD Rom.

VILA, M. T. R.; LIMA, L. C. O.; BOAS, E. V. B. V.; HOJO, E. T. D.; RODRIGUES, L. J.; PAULA, N. R. F. Caracterização química e bioquímica de goiabas armazenadas sob refrigeração e atmosfera modifica. Ciência e Agrotecnologia, v.31, p.1435-1442. 2007.

VINES, H. M.; GRIERSON, W. Handling and physiological studies with the carambola. Proceedings of Florida State Horticultural Science, Florida, v. 79, p. 350-355, 1966.

WILSON, C. W. III. Carambola and Bilinbi. In: Nagy, S.; Shaw, P. E.; Wardowsky, F. S. Fruits of tropical and subtropical origem: composition, properties and uses. Lake Alfred, Florida Science Source, 1990. p.277-301.

YAMASHITA, F.; MIGLIORANZA, L.H. DA S.; MIRANDA, L. DE A.; SOUZA, C. M. DE A. Effects of packaging and temperature on postharvest of atemoya. Revista Brasileira de Fruticultura, v.24, p.658-660, 2002. 